\title{
Article \\ Sleep Habits during COVID-19 Confinement: An Exploratory Analysis from Portugal
}

\author{
Ema Pinto Silva (D) and Sónia Rolland Sobral * $\mathbb{C}$ \\ REMIT (Research on Economics, Management, and Information Technologies), Universidade Portucalense, \\ 4200 Porto, Portugal; 42422@alunos.upt.pt \\ * Correspondence: sonia@upt.pt
}

check for updates

Citation: Silva, E.P.; Sobral, S.R. Sleep Habits during COVID-19 Confinement: An Exploratory Analysis from Portugal. Informatics 2021, 8, 51. https://doi.org/ $10.3390 /$ informatics 8030051

Academic Editors: Guendalina Capece and Flavia Di Costa

Received: 8 July 2021

Accepted: 7 August 2021

Published: 10 August 2021

Publisher's Note: MDPI stays neutral with regard to jurisdictional claims in published maps and institutional affiliations.

Copyright: (c) 2021 by the authors. Licensee MDPI, Basel, Switzerland. This article is an open access article distributed under the terms and conditions of the Creative Commons Attribution (CC BY) license (https:// creativecommons.org/licenses/by/ $4.0 /)$.

\begin{abstract}
COVID-19 pandemic consequences are tragic, and many problems will persist after the health problem ends. Some studies have focused on mental health issues, reporting worrying percentages. It is known that there is a bidirectional relationship between mental health and sleep quality, and it would be expected that sleep would be affected by the pandemic. In order to know the Portuguese people's habits before and during the confinement, we carried out a survey of 188 people aged 13 to $84(38 \pm 15)$ to find out the most frequent sleep patterns, habits and disorders before and during confinement. With this survey it was also intended to measure the most frequent changes in sleep patterns, habits, and disturbances on the general population and according to demographic data (gender, age group and professional status), sleep disorders arise, perceptions about sleep during confinement and if Portuguese think that in the future the sleep patterns will be the pre or during outbreak. Results indicate that, comparing before and during confinement, there is a slight correlation between gender and sleep disorders (before vs. during), a correlation between age group and professional status time to wake up, and between professional status and sleep disorders, and a strong correlation between the professional situation and changes in the invigorated feeling level $(p<0.001)$. Support for mental health and interventions to improve sleep quality should be offered to the population in general, and, according to our study, the Portuguese population.
\end{abstract}

Keywords: COVID-19 pandemic; sleeping habits; survey; Portugal

\section{Introduction}

On 11 March 2020, the Director-General of the World Health Organization defined COVID-19 as a pandemic [1]. This pandemic will forever mark those who lived through it. We do not know the extent of the consequences for the world, but we already have enough information to know that a pandemic crisis has brought countless disasters: not only the obvious ones related to health and the number of people who lost their lives because of the virus, but also related to economic and social aspects, as others. Many studies have been published on the effects of the outbreak on people. Huang and Zhao [2], early in the pandemic, identified a major mental health problem in the Chinese public, especially young people (because they think a lot about the outbreak) and health professionals-two groups that were at high risk in terms of psychological problems. Other studies reveal alarming numbers: $69 \%$ of a study participants revealed clinically relevant anxiety, 31\% depressive symptoms, and 20\% significant post-traumatic stress symptoms [3], 30\% of individuals have clinically significant levels of anxiety, depression, and stress [4]. Literature is not always clear on who are the most vulnerable, but it often reports women, young people, unemployed, and patients with prior mental or psychiatric illnesses [5]; another study found that symptoms of anxiety or depression and trauma were predicted by early age, presence of children at home and high estimates of personal risk; higher levels of anxiety and depression were also predicted by low income, loss of income and pre-existing health conditions in self and others, with specific anxiety levels about COVID-19 being 
higher in older participants [6]. A survey concludes that female gender, negative affect, and detachment were associated with higher levels of depression, anxiety, and stress; having an acquaintance infected was associated with increased levels of both depression and stress, whereas a history of stressful situations and medical problems was associated with higher levels of depression and anxiety; having a family member infected associated to higher levels of anxiety and having a family member who had to work outside their domicile associated to higher stress [7]. Justo-Alonso et colleagues provides evidence that the negative psychological impact of the COVID-19 pandemic hits young people most strongly [8]. Many studies have focused on health workers [9,10], others on the elderly [11] and others on children [12]. University students have been the target of several studies pointing them as the most affected public [13-15]. It is not conclusive for us which groups are most affected, but we realize that many report problems related to emotional well-being associated to the pandemic.

Different literature sources suggest the quality of sleep is associated with symptoms such as depression [16]. Other related studies carried out during the pandemic associate sleep with factors related to isolation, quarantine, anxiety, stress, or financial losses [17]. As it is strongly involved in such important functions, such as the restoration of brain metabolism, consolidation of memory and learning, decision-making, emotional self-regulation, and building social relationships, sleep is undoubtedly "vital for human beings" [18]. There are studies that show a bidirectional relationship between mental health and sleep: depression, anxiety, bipolar disorder, and other conditions tend to lead to sleep problems, and, at the same time, insufficient sleep, including insomnia, may be a contributing factor to the onset and the worsening of mental health problems [19]. For these reasons, it is necessary to verify the sleep disorders caused by the pandemic, especially in the confinement phases. Several studies have been published that relate the quality of sleep to the period of confinement, not only in China but throughout the world, namely in European countries [20], Spain [21] and Italy [22]. Each country has its own dynamics in terms of sleeping habits: for example, the traditional Mediterranean nap, or siesta, is not widely used in other countries. This is the reason the sleep consequences of the pandemic period can be different depending on the country. In Portugal, we highlight three studies carried out related to sleep and confinement: one of them assesses the quality of sleep of respiratory patients [23], another evaluates sleep disorders among children during social distancing, and its association with parental perception of child's oral hygiene [24] and another one evaluates sleep and awakening quality during COVID-19 [25]. We thought it was important that a study be done with the Portuguese population during the confinement, in a comprehensive way and not focused on a specific population, doing it to examine the Portuguese population broadly, rather than looking at specific subgroups.

This article reports a new investigation that aims to identify the habits and sleep disorders before and during confinement, reporting the changes occurred during this period. We tried to verify these modifications according to some demographic factor (gender, age group and professional situation), to identify the sleep disorders of the Portuguese during the confinement and to understand the perception the Portuguese have about their sleep during confinement, as well as what the Portuguese think the quality of their sleep will be when the pandemic ends. We conducted a survey of 188 people of varying profiles, being the most frequent profile women $(82.98 \%)$, aged 20 to 29 years $(29.26 \%)$ and with the professional status of employees $(61.7 \%)$. The article is divided into previous studies, methodology, results, discussion, and conclusions.

\section{Previous Studies}

In the studies that have been published, several instruments are reported. In this paragraph we list these instruments and show a quick description of each one. Athens insomnia scale (AIS) is a self-assessment psychometric instrument designed to quantify sleep difficulty base. It consists of eight items: the first five pertain to sleep induction, awakenings during the night, final awakening, total sleep duration, and sleep quality; 
while the last three refer to well-being, functioning capacity, and sleepiness during the day [26]. The Epworth sleepiness scale (ESS) is a simple, self-administered questionnaire that provides a measure of the subject's overall daytime sleepiness level [27]. Generalized anxiety disorder (GAD) is often used as a residual diagnosis for individuals who did not meet diagnostic criteria for another anxiety disorder [28]. The general self-efficacy scale (GSE) is an instrument for measuring general self-efficacy [29]. The morningnesseveningness questionnaire (MEQ) is a self-assessment questionnaire to measure whether a person's circadian rhythm (biological clock) produces peak alertness in the morning, in the evening, or in between [30]. The Pittsburgh sleep quality index (PSQI) is a selfrated questionnaire which assesses sleep quality and disturbances over a one-month time interval using nineteen individual items to generate seven "component" scores: subjective sleep quality, sleep latency, sleep duration, habitual sleep efficiency, sleep disturbances, use of sleeping medication, and daytime dysfunction [31]. The Regensburg insomnia scale (RIS) is a self-rating scale to assess cognitive, emotional, and behavioral aspects of psychophysiological insomnia with ten items [32]. Zung's self-rating anxiety scale (SAS) is a norm-referenced screener that has been shown to discriminate anxiety from mood disorders [33]. Stanford acute stress reaction questionnaire (SASRQ) was developed to evaluate anxiety and dissociation symptoms in the aftermath of traumatic events, following DSM-IV criteria for acute stress disorder [34]. The social support rate scale (SSRS) is used to measure the type and levels of social support received [35].

The aforementioned study by Huang and Zhao used a cross-sectional survey in China with demographic variables, knowledge related to COVID-19, GAD, depressive symptoms and sleep quality (the last three with percentages of $35.1 \%, 20.1 \%$ and $18.2 \%$, respectively) and concluded that younger people were more related to GAD, older people with depressive symptoms and that health professionals were more likely to have poor sleep quality [2]. Xiao et colleagues, also in early 2020 in China, concluded that low levels of social capital have been associated with anxiety and stress that are associated with reduced sleep quality; high levels of social capital were positively associated with higher quality of sleep [36]. An online questionnaire concluded that being a woman, having an income monthly between 1000 and 5000 or $>5000 \mathrm{CNY}$, not exercising and having a higher education level (baccalaureate and higher) were a risk factor for sleep disorder [37]. Nearly $50 \%$ of study participants reported poor sleep quality, which was associated with a more negative emotional tone and more mentions of money or finance-related words [38]. An online survey based in Italy helped to conclude that young people and women, as well as those with doubts about possible infection with COVID-19 and greater fear of direct contact with people infected with COVID-19 were at an increased risk of developing sleep disorders. As well as higher levels of anxiety and distress [39]. In addition, from Italy, a study reports that women and participants with chronic conditions were associated with a higher prevalence of sleep disorders [40]. Ramos-Padilla et al. analysed the sleep quality and eating habits of Ecuadorian inhabitants during confinement, and found that sleep quality differs according to gender, being worse in women, both in all sleep components, quality, and total score [41]. There are very interesting studies, for example, based on the Moroccan population, where it was found that false beliefs about the understanding of sleep were prevalent and presented a risk factor for sleep disorders, anxiety, and depressive symptoms [42]. A study based on the general population of India found that, compared to the pre-lockdown period, there was a change in bedtime hours and later waking up, with reduced night-time sleep and increased daytime naps, especially for individuals who work, except health professionals. This study associates' reductions in sleep duration with depressive symptoms but concludes that it is unclear whether sleep deterioration produces psychological distress or vice versa [43]. A Facebook research study aimed to investigate sleep disturbances and suicidal thoughts during the COVID-19 pandemic in Taiwan, and found that $55.8 \%$ of participants reported sleep disturbances and $10.8 \%$ reported having suicidal thoughts, suggesting an association with greater concern with COVID-19, more serious impact of COVID-19 on social interaction, less perceived social support, more 
serious academic/occupational interference due to COVID-19, less support specified by COVID-19 and worse physical health self-reported were significantly associated with sleep disturbances [44]. To assess sleep problems and the use of sleeping pills, a general crosssectional study was conducted in France, which found that $74 \%$ of participants reported sleep problems (previously it was $49 \%$ ), with women reporting more sleep problems than men, young people (aged 18-34 years) reported sleep problems slightly more often than older people, $41 \%$ of participants reported taking sleeping pills since the start of the lockdown (before it was 16\%) [45]. The aim of Franceschini and colleagues was to study sleep quality and its connection to distress levels and to assess how lifestyle changed in the Italian population during confinement. They concluded that $55.32 \%$ of participants reported poor sleep quality, and that people with poor sleep revealed several risks during outbreak restrictions: female gender, living in central Italy, having someone close to them who died of COVID-19, markedly altered sleep-wake rhythms by earlier or delayed habitual bedtime, earlier habitual wake-up time and reduced number of afternoon naps, and extremely severe levels of stress, anxiety, and depression [46]. A study, which had as respondents' people from six different countries (Greece, Switzerland, Austria, Germany, France, and Brazil), concluded that confinement affected people's sleep in different ways, depending on age, education level, occupation, and country of residence [47].

Social support during confinement was assessed in a cross-sectional survey that found a risk of high levels of symptoms of minor depression in individuals who reported higher levels of social support compared to those with low perceived social support, and those with high support had a $52 \%$ lower risk of poor sleep quality compared to those with low social support [48]. Leone et al. show that sleep is later and longer on weekdays with less social jetlag during the lockdown compared to a control condition in the same individuals [49].

In a survey of participants from Mexico, $60 \%$ of men and $79 \%$ of women reported poor sleep quality, with young women more likely to be affected by social isolation [50]. Ubara and colleagues assessed changes in depression, sleepiness, insomnia, and sleep habits in relation to the degree of self-isolation and the effects of changes in sleep habits and social interactions on depression, insomnia and sleepiness during coronavirus disease pandemic in a clinical population in Japan and concluded that self-isolation due to COVID-19 had relatively small one-year effects on depression, sleepiness, and insomnia [51].

A study of 53 Austrian women shows that physical exercise prescribed by personal training has been shown to be successful in reducing the deterioration of sleep quality due to the stress caused by the pandemic situation [52]. One study investigated changes in physical activity, sleep time and body weight before and during COVID-19 in South Korea and found that participants who slept less than $7 \mathrm{~h}$ decreased by $3.6 \%$, while those who slept more than $9 \mathrm{~h}$ increased this value. [53]. Another study assesses the associations between physical activity, stress level and sleep quality during the COVID-19 pandemic lockdown, having physical activity decreased for $50 \%$ of respondents, a moderate or high level of stress being found in $57 \%$ and $29 \%$, respectively, and $64 \%$ of them reporting poor sleep. The results of the study indicate that daily physical activity volume may be a predictor of stress level and sleep quality in adults during the COVID-19 pandemic outbreak, associating a low level of stress and good quality sleep with one level. Moderate physical activity (at least $70 \mathrm{~min}$ a day, involving different intensities) [54]. Kontsevaya et colleagues presented a study to assess and analyse the impact of COVID-19 on levels of physical activity and sleep among adults in Russia, concluding that respondents' physical activity and sleep hygiene were adversely affected during COVID-19 [55]. An online survey based in Australia, including measures such as depression, anxiety, stress, physical activity, sleep, alcohol intake and smoking, reported finding in women, people who are not in a relationship, in the lowest income category, aged 18-45 or with a chronic illness, significantly higher scores in one or more states of psychological distress, noting also that negative changes in physical activity, sleep, smoking, and alcohol intake were associated with greater symptoms of depression, anxiety and stress [56]. 
Many of the studies focused on young people and students: high school students were asked about their usual sleeping and wakeup times, verifying that the respondents delayed bedtime and waking times, as well as changed the chronotype to dusk during the COVID19 pandemic [57]. Like some of the studies are focused on the mental health of students, some research studied the effect of sleep during confinement in this population. It is reported that changes in bedtime, sleep latency, worsening of sleep quality and symptoms of insomnia during outbreaks, being the impact of delayed time sleeping and awakening, were more pronounced in students [58]. A study of people under the age of 18 found a significant delay in bedtime and bedtime in general [59]. A study based on responses from 20 Spanish young adults revealed that during the COVID-19 outbreak, behaviours changed, with participants spending less time engaging in physical activity, sitting more, spending more time using the smartphone and sleeping more hours [60]. The focus of the study by Romero-Blanco and colleagues was the difference in sleep quality of nursing students before and during the lockdown, and it was found that students spent more time in bed and the overall sleep quality was worse during the lockdown. Differences were observed in women, first-year students, second-year students, alcohol consumers, those of normal weight and those living with their families [61]. Caregivers of children aged one to five years in Chile completed an online survey with information about the child's movement behaviours before and during the pandemic, as well as family characteristics; it was found that the time spent on physical activity decreased, recreational screen time and sleep duration increased, but sleep quality decreased. From the study it can be seen that those who have space to play at home and living in rural areas experienced an attenuated impact of the pandemic restrictions on their levels of physical activity, screen time and sleep quality, but older children, those whose caregivers were aged 35-45 years and had higher levels of education, and those living in apartments had more changes, especially a decrease in total physical activity and an increase in screen time [62]. Abid et al. presented a study aiming to investigate the effect of COVID-19 home confinement on sleep quality, screen time and physical activity in Tunisian children with a special focus on gender differences, and concluded that the results revealed that confinement following COVID-19 had a negative effect on all parameters considered, with significant association of gender with sleep disturbances, subjective sleep quality, global PSQI and nocturnal scores, and global screen time with poorer sleep and longer screen time in girls compared to boys during home confinement [12]. A survey of sixty-six university students from China, focusing on reaction to the COVID-19 death count, showed a direct negative impact on overall sleep quality, as well as an indirect impact on general negative emotions [63].

A study investigated whether sociodemographic variables, changes in physical activity and sleep quality in the pre-lockdown period were predictors of change in mental wellbeing in elderly people in quarantine in Europe, Western Asia, North Africa and the Americas, verifying that the COVID-19 lockdown negatively affected physical activity and sleep patterns, and the change in the total PSQI score and the total energy expenditure of physical activity were significant predictors for the decrease in mental well-being [11].

Many of the studies focused on health professionals: Mota and colleagues studied the Brazilian healthcare professional population and found that about two-thirds of the sample had some sleep-related complaints during the pandemic [9]. A research study conducted among frontline medical staff in the fight against COVID-19 reported that respondents' overall sleep quality was poor, being reported moderate insomnia in $61.67 \%$, and severe insomnia in $26.67 \%$ [10]. To assess the effect of the COVID-19 outbreak on the sleep quality of healthcare professionals at a paediatric hospital in Wuhan, China, a questionnaire was conducted that concluded that $38 \%$ of participants were identified as having sleep disorders. The findings show that sleep was independently associated with single-child exposure to patients with COVID-19 and depression [64]. Xiao et colleagues used an observational study to determine the effects of social support on sleep quality and function of 180 medical teams who treated patients with COVID-19 concluding that levels of anxiety, stress and self-efficacy were dependent on sleep quality and social support [65]. Kim-Godwin et 
colleagues conducted a study of sleep quality among female nurses in the United States during the onset of the pandemic, and it was found that nurses working part-time, with a lower perception of physical health, with a lower self-care score for self-regulation, and greater stress at work had worse sleep quality [66]. A study aimed to investigate levels of anxiety and sleep quality among first- and second-line health professionals during the COVID-19 pandemic, found that $25.92 \%$ of respondents experienced moderate to severe anxiety, with severe symptoms of anxiety observed in $11.41 \%$ of first-line, compared to $9.20 \%$ of second-line health professionals, and respectively $84.6 \%$ and $79.9 \%$ in levels of poor sleep quality [67].

Summarizing this section: first we listed some of the instruments that are used in studies, then we approached studies for the general population and in different countries and continents (those that relate sleep with physical activity or social isolation), then we approached the studies aimed at a specific audience, namely children and young people, university students, the elderly or health professionals. We verified that there are several excellent studies, but we do not seem to be sure about the most affected population (women, elderly, university students, for example). It seems more sensible to us to start with this information and try to find the Portuguese reality in a comprehensive way.

\section{Methodology}

\subsection{Research Questions}

To achieve the objectives under reflection, this investigation intends to answer the following questions:

RQ1: What were the most common patterns, habits, and sleep disorders of the Portuguese in general in the period before confinement?

RQ2: What were the most common patterns, habits, and sleep disorders of the Portuguese in general in the period during confinement?

RQ3: What were the most common changes in patterns, habits, and sleep disorders of the Portuguese during the period of confinement compared to the previous period?

RQ4: Do changes in patterns, habits, and sleep disturbances during the period of confinement compared to the previous period differ according to demographics (gender, age group and professional status)?

RQ5: Did sleep disorders arise for the Portuguese during confinement? If so: what kind of sleep disorders?

RQ6: What were the perceptions of the Portuguese about their sleep during confinement? Do the Portuguese think that in the future the sleep patterns will be those of confinement or those of pre-confinement?

\subsection{Study Design}

The answers to these questions are very important in portraying sleep patterns, habits, and disorders before and during confinement and in order find out what has changed. However, our questions are not only intended to portray typical Portuguese, but also to know whether demographic aspects (gender, age group and professional status) have an influence on changes between pre and during the confinement period. It is also interesting to know the perception of the Portuguese in terms of what has changed and what is their perspective in relation to the future regarding their sleeping patterns and habits. To this end, a survey was developed on Google forms, consisting of four sections and 21 questions. The survey was voluntary and non-commercial. The link to the form was made available to participants using the project's different social networks. The target audience was not limited to any specific age group or level of qualification, thus seeking to collect a larger and more diverse sample.

\subsection{Data Collection}

The inquiry was opened in the last two weeks of February 2021. The following figure (Figure 1) shows the monthly data of COVID-19 cases and deaths in Portugal since March 
2020 to March 2021 [68,69]. We can see a first wave in April 2020, another in November 2020 and a third, much more serious, in January and February 2021 [70,71].

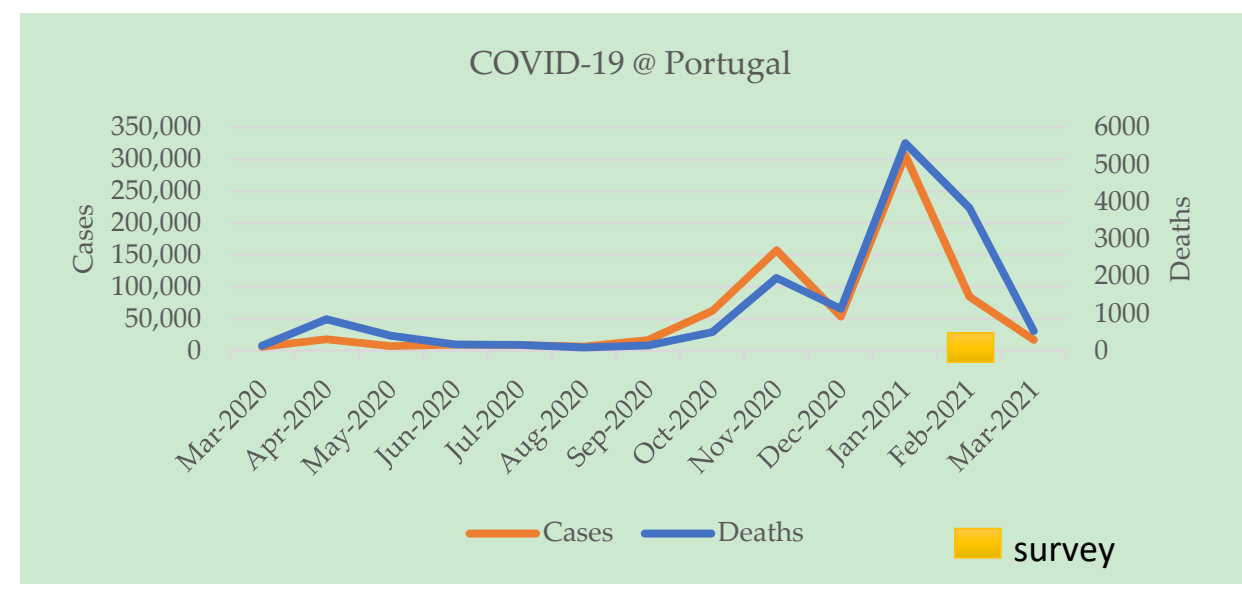

Figure 1. COVID-19 cases and deaths, Portugal, and the survey moment.

\subsection{Ethical Statement}

At the beginning of the questionnaire, respondents were faced with information about the survey (objectives and e-mail addresses of researchers, for example), as well as the question of whether they would be available to respond to it. Only after consent was given did the questions arise. Respondents could, at any time, withdraw from answering the questionnaire without providing any justification.

\subsection{Mesures}

The four sections of the survey were divided into demographics (gender, year of birth and professional status), pre-confinement, confinement, and perception of changes/future. Sections two and three consisted of questions about bedtime, waking up time, minutes to fall asleep, average number of hours of daily sleep, levels of feeling refreshed when waking-up ( 0 terrible to 5 excellent), sleeping habits during the day, noticeable sleep disorders - and if they exist which ones they relate to from a list of possible disorders according to the International Classification of Sleep Disorders - Third Edition [72]: insomnia, sleep-related breathing disorders (sleep apnea), central disorders of hypersomnolence (narcolepsy), parasomnias (nightmares), sleep-related movement disorders (bruxism) and other sleep disorders.

We used the $p$-value, or probability value, which is a number that describes the probability that the null hypothesis is true, that is, the data occurred randomly. The $p$-value is between 0 and 1; the smaller it is, the stronger the evidence that the null hypothesis should be rejected.

\section{Results}

\subsection{Participants Demographics}

We validated 188 responses in the questionnaires. Most participants were female, representing $82.98 \%$ of the total with 156 responses. The average age was 38.38 years, with $28.72 \%$ being in the $20-29$ age group and $20.1 \%$ in the $40-49$ age group, aged between 13 and 84 years, with a mean age of 38 , standard deviation $15.61 .7 \%$ were employed, $8.51 \%$ unemployed, $20.21 \%$ student, $3.19 \%$ students with parallel jobs and $6.38 \%$ retired.

\subsection{Pre-Confinement Sleep Habits}

The participants were asked to respond based on the sleep habits they maintained before the first COVID-19 pandemic confinement period began. First, they were asked about the time they used to go to bed; almost half of the sample, $41 \%$, had the habit of going to bed between 23:00 and 00:00. A total of 30\% replied that they used to go to bed 
between 20:00 and 23:00. Further, 24\% of the sample answered they used to go to bed after 24:00 and only 5\% in the interval between 21:00 and 22:00. Most respondents (50.53\%) reported waking up normally between 7 and $8 \mathrm{am}$, before confinement. When asked how many hours on average they slept previously, half of the sample claimed to sleep between $7-8 \mathrm{~h}$ a night, with a mean of 7.2 , standard deviation 1.3 . In addition, $27 \%$ of the sample indicated that they used to sleep between $5-6 \mathrm{~h}$ a night. A total of $41 \%$ of respondents responded that it took 10 to $15 \mathrm{~min}$ to fall asleep. People who took less than $10 \mathrm{~min}$ to fall asleep are the second most significant percentage, $25 \%$ of the sample, with a mean of 16.6, standard deviation 10.4 min. Further, 82 participants (43.61\%) reported feeling refreshed after a night's sleep. On the other hand, 26 of the respondents (13.82\%) answered they did not feel invigorated after a night's sleep. Before the first confinement, $51 \%$ of the participants woke up between 07:00 and 08:00 in the morning, with 19\% getting out of bed between 08:00 and 09:00 in the morning. The mean of the perceived revigorated level was 3.4, standard deviation of 0.9. We asked if the participants had the habit of sleeping during the day, the vast majority corresponding to $79 \%$ of the sample answered that they did not and only $21 \%$ said they used to sleep during the day before confinement. Regarding sleep disorders, $29 \%$ of the sample suffered from sleep-related disorders, $71 \%$ have reportedly no issues.

\subsection{Confinement Sleep Habits}

Regarding sleep habits during confinement and as an answer to the question of whether the participants' bedtime would have changed with confinement: $41.49 \%$ of the participants reported having changed their bedtime. Thus, the remaining $58.51 \%$ did not change their bedtime. Regarding the number of hours slept per night in confinement periods, most of the sample, 85 participants $(45.21 \%)$, slept between 7 to $8 \mathrm{~h}$ per night, while 56 participants $(29.79 \%)$ slept between 5 and $6 \mathrm{~h}$ a night, with a mean 7.4, standard deviation 1.5. When asked how long (in minutes) the respondents needed to fall asleep during confinement, it was found that $34.67 \%$ took between 10 to $15 \mathrm{~min}$ to fall asleep and that $26.6 \%$ needed more than $30 \mathrm{~min}$ to fall asleep, with a mean of 19.8, standard deviation $11.1 \mathrm{~min}$. The mean of the perceived revigorated level was 3.2, standard deviation of 0.98 . When asked whether they usually fell asleep throughout the day during confinement periods, 111 of the 188 respondents (59.04\%) replied that they did not, and $77(40.96 \%)$ tended to fall asleep during the day during confinement periods. When asked about sleep-related disorders during confinement, $61.7 \%$ participants said they did not have any sleep disorders.

\subsection{Reported Sleep Disorders}

A total of 55 of the participants (29.26\%) reported sleep disorders before confinement and $72(38.30 \%)$ reported sleep disorders during confinement. It appears that $39.6 \%$ of people who had no sleep disorders before confinement reported having problems during the confinement. It appears that $66 \%$ of participants who reported sleep disorders preconfinement, had no sleep problems during confinement. The next table (Table 1) shows demographics (gender, age group, professional situation), pre-confinement sleep habits, confinement sleep habits, and sleep disorders: before vs. during confinement.

Of the 72 participants who reported sleep disorders during confinement, they identified (one or more responses): sleep apnea (1.39\%), bruxism (8.33\%), insomnia $(83.33 \%)$, narcolepsy (1.39\%) and nightmares (50.00\%). 
Table 1. Demographics (gender, age group, professional situation), pre-confinement sleep habits, confinement sleep habits, sleep disorders: before vs. during confinement.

\begin{tabular}{|c|c|c|c|c|c|}
\hline Gender & & Age Group & & Professional Situatio & \\
\hline Male & $17.02 \%$ & $<20$ & $7.98 \%$ & Unemployed & $8.51 \%$ \\
\hline \multirow[t]{5}{*}{ Women } & $82.98 \%$ & $20-29$ & $28.72 \%$ & Employee & $61.70 \%$ \\
\hline & & $30-39$ & $15.43 \%$ & Student & $20.21 \%$ \\
\hline & & $40-49$ & $20.21 \%$ & Stud-Employee & $3.19 \%$ \\
\hline & & $50-59$ & $18.62 \%$ & Retired & $6.38 \%$ \\
\hline & & $60+$ & $9.04 \%$ & & \\
\hline \multicolumn{2}{|l|}{ When sleep (time) } & \multicolumn{2}{|l|}{ When wake up (time) } & \multicolumn{2}{|c|}{ Time to fall asleep (minutes) } \\
\hline 21:00-22:00 & $4.79 \%$ & Before 6:00 & $6.38 \%$ & $<10 \mathrm{~m}$ & $25.00 \%$ \\
\hline $22: 00-23: 00$ & $29.79 \%$ & 06:00-07:00 & $17.02 \%$ & $10-15 \mathrm{~m}$ & $39.89 \%$ \\
\hline 23:00-00:00 & $40.96 \%$ & 07:00-08:00 & $50.53 \%$ & $20-30 \mathrm{~m}$ & $19.15 \%$ \\
\hline \multirow[t]{2}{*}{ After 00:00 } & $24.47 \%$ & 08:00-09:00 & $19.15 \%$ & $+30 \mathrm{~m}$ & $15.96 \%$ \\
\hline & & After 9:00 & $6.91 \%$ & & \\
\hline \multicolumn{2}{|l|}{ Invigorated $(0-5)$} & \multicolumn{2}{|l|}{ How much (hours) } & \multicolumn{2}{|l|}{ Sleep during the day } \\
\hline 1 & $2.13 \%$ & $<5 \mathrm{~h}$ & $4.79 \%$ & Yes & $20.74 \%$ \\
\hline 2 & $10.64 \%$ & $5-6 \mathrm{~h}$ & $26.60 \%$ & No & $79.26 \%$ \\
\hline 3 & $34.57 \%$ & $7-8 \mathrm{~h}$ & $56.91 \%$ & Sleep disorders & \\
\hline 4 & $43.62 \%$ & $9-10 \mathrm{~h}$ & $9.04 \%$ & Yes & $29.26 \%$ \\
\hline 5 & $7.98 \%$ & $+10 \mathrm{~h}$ & $0.53 \%$ & No & $70.74 \%$ \\
\hline \multicolumn{2}{|c|}{ Difference (sleep time) } & \multicolumn{2}{|c|}{ When wake up (time) } & \multicolumn{2}{|c|}{ Time to fall asleep (minutes) } \\
\hline Yes & $41.49 \%$ & Before 6:00 & $6.91 \%$ & $<10 \mathrm{~m}$ & $17.55 \%$ \\
\hline \multirow{4}{*}{ No } & $58.51 \%$ & 06:00-07:00 & $7.98 \%$ & $10-15 \mathrm{~m}$ & $34.57 \%$ \\
\hline & & 07:00-08:00 & $29.79 \%$ & $20-30 \mathrm{~m}$ & $21.28 \%$ \\
\hline & & 08:00-09:00 & $32.98 \%$ & $+30 \mathrm{~m}$ & $26.60 \%$ \\
\hline & & After 9:00 & $22.34 \%$ & & \\
\hline \multicolumn{2}{|c|}{ Invigorated (0-5) } & \multicolumn{2}{|c|}{ How much (hours) } & \multicolumn{2}{|c|}{ Sleep during the day } \\
\hline 0 & $2.13 \%$ & $<5 \mathrm{~h}$ & $5.32 \%$ & Yes & $40.96 \%$ \\
\hline 1 & $3.72 \%$ & $5-6 h$ & $29.79 \%$ & No & $58.51 \%$ \\
\hline 2 & $12.23 \%$ & $7-8 \mathrm{~h}$ & $45.21 \%$ & & \\
\hline 3 & $44.68 \%$ & $9-10 \mathrm{~h}$ & $18.09 \%$ & Sleep disorders & \\
\hline 4 & $32.45 \%$ & $+10 \mathrm{~h}$ & $1.60 \%$ & Yes & $38.30 \%$ \\
\hline \multirow[t]{2}{*}{5} & $4.79 \%$ & & & No & $61.70 \%$ \\
\hline & \multicolumn{5}{|c|}{ Disorders (During Confinement) } \\
\hline \multirow[t]{2}{*}{ No } & $79.26 \%$ & & & No & $60.40 \%$ \\
\hline & & & & Yes & $39.60 \%$ \\
\hline \multirow{2}{*}{ Yes } & $20.74 \%$ & & & No & $66 \%$ \\
\hline & & & & Yes & $33 \%$ \\
\hline
\end{tabular}

\subsection{Perceptions Regarding Sleep and Confinement}

A total of $60.64 \%$ of participants said they perceived a change in sleep patterns or sleep disorders, $26.60 \%$ do not have this perception and $12.77 \%$ answered that perhaps sleep has undergone changes. A total of $67.55 \%$ think that sleep habits will return to normal after confinement, but $32.45 \%$ think that symptoms will persist in the long term. Of those who reported having had changes in sleep patterns or disturbances, $36.84 \%$ predicted that the problem will maintain after the end of the confinement.

\subsection{Changes in the Period before vs. during Confinement}

\subsubsection{Bedtime}

A total of $58.51 \%$ of respondents revealed that they did not change their bedtime during confinement. Analysing the numbers, we realised that bedtime changes during 
confinement compared to the period before March 2020 were more reported by women $(44.23 \%)$ than by men $(28.13 \%)$, in the lower age groups (less than 20 years old by $53.33 \%$ and $20-29$ years old by $55.56 \%$ ) than in the upper age groups (50-59 years old by $25.71 \%$, 60 years old or more by $29.41 \%)$. Students $(60.53 \%)$ were the group that reported the most changes with bedtime, followed by unemployed (43.75\%). Contrary to this, only $33 \%$ of the retired reported a change.

\subsubsection{Sleeping Duration}

A total of $15.96 \%$ of the participants slept less in the confinement than in the previous period, $60.11 \%$ did not see any change in the number of hours of sleep and $23.94 \%$ started to sleep more hours during the confinement than in the previous period. Regarding the sleeping duration, and regarding the participant's gender, there are no significant differences between during and before confinement. The age group under 20 years old seems to be the one which started to sleep less (26.67\%); the age group from 40 to 49 years old maintained their sleep hours, similarly to the 20 to 29 years old group $(27.7 \%)$ reported having started to sleep more. The age group under 20 years old was the one that suffered the most changes in the number of hours of sleep: less than half $(46.67 \%)$ maintained the same number before and during confinement. None of the respondents who are students with part-time jobs reported fewer hours of sleep. On the other hand, none of the retired participants reported that they spent more hours sleeping during confinement.

\subsubsection{Time to Fall in Sleep}

A total of $4.79 \%$ of respondents took less time to fall asleep during confinement than in the previous period, $67.55 \%$ the same and $27.66 \%$ took longer to fall asleep. Regarding the time to fall asleep, and regarding the gender of the participants, there are no significant differences between, during and before confinement. Age groups under 20 years old, 60 years old or even older say they took less time to fall asleep than before confinement (insignificant percentages of $13.33 \%$ and $11.76 \%$ respectively). Again, it is the lower age groups (less than 20 years old and 20-29 years old) that took longer to fall asleep during confinement than previously ( $33.33 \%$ and $34.55 \%)$. As for the professional situation, it is the retired and unemployed who report taking less time to fall asleep during confinement than previously ( $16.67 \%$ and $12.5 \%$ respectively), while students with part-time jobs report that it takes longer to fall asleep (50\%).

\subsubsection{Wake Up Time}

Half of the participants woke up at the same time during the confinement as in the previous period, $43.52 \%$ woke up later and $6.38 \%$ earlier. As for the times they usually wake up, mostly men kept the habitual schedule $(65.23 \%)$, while women started waking up later (47.44\%). The oldest group, 60 years old or more, was the main group who reported waking up at the same time $(82.35 \%)$, while the youngest, under 20 years old, was the one waking up later during the confinement compared to the period before confinement $(66.67 \%)$. The retired were the group which mostly woke up at the same time (75\%), while students reported waking up later in confinement than in the period prior to confinement $(73.68 \%)$.

\subsubsection{Invigorated}

The surveyed men reported having a less invigorating sleep than previously $(78.13 \%$ men and $59.62 \%$ women). Sleep seems to be more invigorating to the younger participants; contrary to this, sleep was less invigorating during confinement to the older participants: $76.47 \%$ of 60 or more years old report less vigorous sleep and $46.67 \%$ of the respondents under 20 years old report more restorative sleep than previously. It is the retired $(83.33 \%)$ who report less restorative sleep and the students $(52.63 \%)$ who report more restorative sleep. 


\subsubsection{Sleeping during the Day}

There are no significant gender differences in terms of sleeping during the day before or during confinement. A total $71.05 \%$ of participants aged 40 to 49 did not sleep during the day (neither before nor during confinement); $53.33 \%$ of young people under 20 reported not sleeping during the day before confinement but started to take a nap during confinement. Further, $10.71 \%$ of participants aged $30-39$ years reported that they stopped sleeping during the day during the period of confinement, in contrast to what they used to do before confinement. In addition, $27.27 \%$ of participants between 20 and 29 years old reported they maintained the habit of sleeping during the day. A total of $66 \%$ of the retired reported that they did not have the habit of sleeping during the day, before or during confinement.

\subsubsection{Sleeping Disorders}

$75 \%$ of male respondents said they had no sleep disorders (neither before nor during confinement), and $42.95 \%$ of women said the same. Only $6.25 \%$ of men said that with the confinement they started to have sleep disorders, and $26.28 \%$ of women surveyed said the same. $32.73 \%$ of the interviewees with 20 to 29 years old reported experiencing new sleep disorders during confinement. A total of $29.41 \%$ of participants aged 60 or over said they continued to have sleep disturbances during the confinement. Further, $50 \%$ of the students with part-time work reported experiencing new sleep disturbances during confinement. Further, $18.1 \%$ of the fully employed interviewees said that they no longer had, during the confinement period, the usual sleep disorders.

Table A1 shows $p$-value for each change (bedtime, sleep duration, time to fall in sleep, time to wake up, wake up, feel invigorated, during the day, disorders), by demographics (gender, age, and professional situation).

\section{Discussion}

In this section we will discuss the results presented in the Section 3 to answer the research questions. We have chosen, in this section, to list the most frequent answers to identify a pattern and thus better answer our research questions.

\subsection{What Were the Most Common Patterns, Habits and Sleep Disorders of the Portuguese in} General in the Period before Confinement?

The most common patterns, habits, and sleep disorders of the Portuguese in general in the period before confinement were bedtime: 23:00-00:00 (40.96\%), waking up time: 07:00-08:00 (50.53\%), time to fall asleep: 10-15 min (39.89\%), Level $4(0-5)$ of invigorating sleep sensation $(43.62 \%), 7-8 \mathrm{~h}$ of sleep per night $(56.91 \%)$, not sleeping during the day $(79.26 \%)$ and without sleep disorders $(70.74 \%)$.

\subsection{What Were the Most Common Patterns, Habits and Sleep Disorders of the Portuguese in} General in the Period during Confinement?

The most common patterns, habits, and sleep disorders of the Portuguese in general in the period during confinement were bedtime as before confinement $(58.51 \%)$, waking up time; 08:00-09:00 (32.98\%), time to fall asleep 10-15 $\mathrm{min}(34.57 \%)$, Level $3(0-5)$ of invigorating sleep sensation (44.68\%), 7-8 h of sleep per night (45.21\%), not sleeping during the day $(58.51 \%)$ and without sleep disorders $(61.70 \%)$.

\subsection{What Were the Most Common Changes in Patterns, Habits and Sleep Disorders of the} Portuguese during the Period of Confinement Compared to the Previous Period?

The most common changes in patterns, habits, and sleep disorders of the Portuguese during the period of confinement compared to the previous period were: no change in bedtime $(58.51 \%)$, no change in waking up time $(50 \%)$, no change in time to fall asleep $(67.56 \%)$, lower feeling of invigorating sleep $(62.77 \%)$, same number of hours of sleep per night $(60.11 \%)$, did not sleep at all during the day in both periods $(53.72 \%)$ and without sleep disorders in both periods (48.4\%). 
5.4. Do Changes in Patterns, Habits and Sleep Disturbances during the Period of Confinement Compared to the Previous Period Differ According to Demografics (Gender, Age Group and Professional Status)?

\subsubsection{By Gender}

By gender and by item considered in the previous section, the most significant changes between the pre-confinement and confinement period are:

Women more than man reported they started waking up later $(47.44 \%$ and $25 \%$, respectively). Male, more than female, reported feeling less invigorated in confinement than before $(78.13 \%$ and $59.62 \%)$. Men, more than woman, reported having no sleep disorders either before or during confinement ( $75 \%$ and $42.95 \%)$, while women more than men, reported they had no sleep disturbances previously but started to experience them during confinement $(26.28 \%$ and $6.25 \%)$. The $p$ value indicates that there is slight correlation between gender and sleep disorders (before vs. during); the $p$-value of the other changes by the gender variable is always greater than 0.005 - which reveals no correlation.

\subsubsection{By Age Group}

By age group and by item considered in the previous section, the changes between the pre-confinement and confinement period are:

The lowest age groups were those who reported having changed bedtime the most (53.33\% under 20 years old and $55.56 \%$ of the $20-29$ age group), in contrast to the older people who changed less (25.71\% 50-59 age group and $29.41 \%$ age group $60+$ years). The participants of the age group under 20 years old reported they started waking up later $(66.67 \%)$ while the older age group (+60 years) was the ones which mostly reported not having undergone changes in the waking up time $(82.35 \%)$. The age group under 20 years old reported feeling more invigorated during confinement compared to the period before confinement $(46.67 \%)$, while those in the older age group (+60 years) reported feeling less invigorated $(76.47 \%)$. A total of $53.33 \%$ of respondents in the younger age group said that before confinement they did not sleep during the day but started to do so. The $p$ value (0.005) indicates that there is a correlation between age group and the change in time to wake up; the $p$-value of the other alterations due to the age variable is always greater than 0.005 - which does not reveal any correlation.

\subsubsection{By Professional Situation}

By professional situation, and by item considered in the previous section, the changes between the pre-confinement and confinement period are as follows:

Students were the professional group that most changed the bedtime $(60.53 \%)$. On the contrary, pensioners and student/workers reported they did not change their bedtime $(66 \%)$. A total of $50 \%$ of student workers said they took longer to fall asleep. The students stated in our survey that they started to wake up later $(73.68 \%)$, while the pensioners are the ones who mostly reported not having undergone changes in the waking up time (75\%). Students mentioned feeling more refreshed during the confinement than in the previous period $(52.63 \%)$, while the pensioner group reported feeling less invigorated $(76.47 \%)$. Further, $42.12 \%$ of students said that before confinement they usually did not sleep during the day but started to do so. In addition, 50\% of student/workers reported that during confinement they started to have sleep disorders, which did not happen previously. The $p$ value (0.001) indicates that there is a significant correlation between the professional situation and changes in the refreshed feeling; $p$ value related to sleep disorders and professional status (0.005) reveals that there is a correlation, although less significant than the previous one; the $p$ value of the other alterations due to the variable of professional status is always greater than 0.005 -which does not show any correlation. 


\subsection{Did Sleep Disorders Arise for the Portuguese during Confinement? If So: What Kind of Sleep Disorders?}

A total of $38.3 \%$ respondents reported sleep disorders during confinement. They identified (one or more responses): insomnia $(83.33 \%)$, nightmares $(50.00 \%)$, bruxism $(8.33 \%)$, sleep apnea $(1.39 \%)$, narcolepsy $(1.39 \%)$.

5.6. Did the Portuguese Perceive Any Changes on Their Sleep during Confinement? Do the Portuguese Think Their Future Sleep Patterns Will Continue to Be the Same as during the Confinement or Will It Go Back to How It Was Pre-Confinement?

A total of $60.64 \%$ of respondents said they perceived a change in sleep patterns or sleep disorders, $67.55 \%$ think that sleep habits will return to normal after confinement.

\section{Conclusions}

With this investigation we were able to portray the habits and sleep quality of the Portuguese, before and during the COVID-19 confinement. We analysed the consequences of the lockdown in terms of sleep patterns-also identifying other related sleep disorders. The sample size is not very large, but it has a dimension that helps us to point out results. This report was sampled in the general population and considering other demographic aspects, such as: gender, age group and professional status.

In the previous section, we were able to answer research questions, namely to know the most common sleep patterns, habits and disorders of the general Portuguese in the previous period and during confinement; to know the most frequent changes in sleep patterns, habits and disorders of Portuguese people during the period of confinement compared to the previous period for the general population and by demographic data (gender, age group and professional status); to know if sleep disturbances appeared for the Portuguese during the confinement; and if so, know what kind of sleep disturbances arose. An attempt was also made to gauge the perceptions of Portuguese people about sleep during confinement and what the Portuguese think about the future of sleep patterns. We found a slight correlation between gender and sleep disorders (before vs. during), a correlation between age group and the change in time to wake up and between professional status and sleep disorders, a strong correlation between the professional situation and changes in the invigorated feeling. A total of $75 \%$ of men and $43 \%$ of women reported no sleep disturbances either before or during confinement. Further, $67 \%$ of young people under 20 years of age reported waking up later in confinement, with the same being reported by $12 \%$ of people aged 60 and over.

As a future work, and when the world is free from this terrible pandemic, we intend to repeat this study and see what changes in sleep patterns and disturbances have been brought to the Portuguese by successive confinements. There are several elements that were not measured in this survey, but which are very important and are potential influencers of sleep quality, such as physical activity, sexual activity, drug use (in addition to alcohol and tobacco), hypertension, obesity, and other diseases, as well as medication. These items potentially influencing sleep quality and associated diseases were considered in this research design and discarded so as not to make the questionnaire (even) longer. At the conclusion, we regret not having included some of these items, so they can be used in a future work.

This work can be useful in helping to understand sleep habits and anticipating associated problems. Support for mental health and interventions to improve sleep quality should be implemented in the population in general, and, according to our study, in the Portuguese population.

Author Contributions: Conceptualization, E.P.S. and S.R.S.; methodology, E.P.S. and S.R.S.; software, S.R.S.; validation, S.R.S.; formal analysis, S.R.S.; investigation, E.P.S. and S.R.S.; resources, E.P.S.; data curation, E.P.S.; writing — original draft preparation E.P.S. and S.R.S.; writing-review and editing, S.R.S.; visualization, S.R.S. supervision S.R.S.; project administration, S.R.S. funding acquisition, S.R.S. Both authors have read and agreed to the published version of the manuscript. 
Funding: This work was supported by the FCT—Fundação para a Ciência e a Tecnologia, I.P. [Project UIDB/05105/2020].

Institutional Review Board Statement: Not applicable.

Informed Consent Statement: Informed consent was obtained from all subjects involved in the study.

Data Availability Statement: The data presented in this study are available on request from the corresponding author.

Conflicts of Interest: The authors declare no conflict of interest.

\section{Appendix A}

Table A1. $p$-value, changes: bedtime, sleep duration, time to fall in sleep, time to wake up, wake up, feel invigorated, during the day, disorders, by gender, age and professional situation.

\begin{tabular}{cccc}
\hline$p$-Value & Gender & Age & Professional \\
\hline Bedtime changes & 0.092 & 0.044 & 0.110 \\
Sleep duration changes & 0.092 & 0.044 & 0.110 \\
Time to fall in sleep changes & 0.243 & 0.605 & 0.066 \\
Time to wake up changes & 0.064 & 0.005 & 0.004 \\
Feeling invigorated changes & 0.142 & 0.056 & 0.000 \\
Sleeping during the day changes & 0.730 & 0.192 & 0.402 \\
Sleeping disorders changes & 0.009 & 0.624 & 0.005 \\
\hline
\end{tabular}

\section{References}

1. World Health Organization. WHO Director-General's Opening Remarks at the Media Briefing on COVID-19-11 March 2020; WHO: Geneva, Switzerland, 2020.

2. Huang, Y.; Zhao, N. Generalized anxiety disorder, depressive symptoms and sleep quality during COVID-19 outbreak in China: A web-based cross-sectional survey. Psychiatry Res. 2020, 288, 112954. [CrossRef]

3. Castelli, L.; di Tella, M.; Benfante, A.; Romeo, A. The Spread of COVID-19 in the Italian Population: Anxiety, Depression, and Post-Traumatic Stress Symptoms. Can. J. Psychiatry 2020, 65, 731-732. [CrossRef]

4. Gutiérrez-Hernández, M.; Fanjul, L.; Díaz-Megolla, A.; Reyes-Hurtado, P.; Herrera-Rodríguez, J.; Enjuto-Castellanos, M.; Peñate, W. COVID-19 Lockdown and Mental Health in a Sample Population in Spain: The Role of Self-Compassion. Int. J. Environ. Res. Public Health 2021, 18, 2103. [CrossRef]

5. Rodríguez-Fernández, P.; González-Santos, J.; Santamaría-Peláez, M.; Soto-Cámara, R.; Sánchez-González, E.; González-Bernal, J. Psychological Effects of Home Confinement and Social Distancing Derived from COVID-19 in the General Population-A Systematic Review. Int. J. Environ. Res. Public Health 2021, 18, 6528. [CrossRef]

6. Shevlin, M.; McBride, O.; Murphy, J.; Miller, J.; Hartman, T.; Levita, L.; Bentall, R. Anxiety, depression, traumatic stress and COVID-19-related anxiety in the UK general population during the COVID-19 pandemic. BJPsych Open 2020, 6, E125. [CrossRef]

7. Mazza, C.; Ricci, E.; Biondi, S.; Colasanti, M.; Ferracuti, S.; Napoli, C.; Roma, P.A. Nationwide Survey of Psychological Distress among Italian People during the COVID-19 Pandemic: Immediate Psychological Responses and Associated Factors. Int. J. Environ. Res. Public Health 2020, 17, 3165. [CrossRef]

8. Justo-Alonso, A.; García-Dantas, A.; González-Vázquez, A.; Sánchez-Martín, M.; DelRío-Casanova, L. How did Different Generations Cope with the COVID-19 Pandemic? Early Stages of the Pandemic in Spain. Psicothema 2020, 32, 490-500.

9. Mota, I.; Sobrinho, G.; Morais, I.D.T. Impact of COVID-19 on eating habits, physical activity and sleep in Brazilian healthcare professionals. Arq. Neuro-Psiquiatr. 2021, 79, 429-436. [CrossRef] [PubMed]

10. Wu, K.; Wei, X. Analysis of Psychological and Sleep Status and Exercise Rehabilitation of Front-Line Clinical Staff in the Fight Against COVID-19 in China. Med. Sci. Monit. Basic Res. 2020, 26, e924085-1-e924085-7. [CrossRef]

11. Trabelsi, K.; Ammar, A.; Masmoudi, L.; Driss, T.; Hoekelmann, A. Sleep quality and physical activity as predictors of mental wellbeing variance in older adults during COVID-19 lockdown: Eclb COVID-19 international online survey. Int. J. Environ. Res. Public Health 2021, 18, 4329. [CrossRef] [PubMed]

12. Abid, R.; Ammar, A.; Maaloul, R.; Souissi, N.; Hammouda, O. Effect of COVID-19-Related Home Confinement on Sleep Quality, Screen Time and Physical Activity in Tunisian Boys and Girls: A Survey. Int. J. Environ. Res. Public Health 2021, 18, 3065. [CrossRef]

13. Volken, T.; Zysset, A.; Amendola, S.; Swormink, A.K.; Huber, M.; von Wyl, A.; Dratva, J. Depressive Symptoms in Swiss University Students during the COVID-19 Pandemic and Their Correlates. Int. J. Environ. Res. Public Health 2021, 18, 1458. [CrossRef]

14. Odriozola-González, P.; Planchuelo-Gómez, A.; Irurtia, M.; Luis-García, R. Psychological effects of the COVID-19 outbreak and lockdown among students and workers of a Spanish university. Psychiatry Res. 2020, 290, 113108. [CrossRef] 
15. Wang, X.; Hegde, S.; Son, C.; Keller, B.; Smith, A.; Sasangohar, F. Investigating Mental Health of US College Students During the COVID-19 Pandemic: Cross-Sectional Survey Study. J. Med. Internet. Res. 2020, 22, e22817. [CrossRef]

16. Chang, K.; Son, S.; Lee, Y.; Back, J. Perceived sleep quality is associated with depression in a Korean elderly population. Arch. Gerontol. Geriatr. 2014, 59, 468-473. [CrossRef]

17. Partinen, M. Sleep research in 2020: COVID-19-related sleep disorders. Lancet Neurol. 2021, 20, 15-17. [CrossRef]

18. Krueger, J.M.; Frank, M.G.; Wisor, J.P.; Roy, S. Sleep function: Toward elucidating na enigma. Sleep Med. Rev. 2016, 28, 46-54. [CrossRef]

19. Freeman, D.; Sheaves, B.; Goodwin, G.; Siriwardena, A.; Espie, C. The effects of improving sleep on mental health (OASIS): A randomised controlled trial with mediation analysis. Lancet Psychiatry 2017, 4, 749-758. [CrossRef]

20. Altena, E.; Baglioni, C.; Espie, C. Dealing with sleep problems during home confinement due to the COVID-19 outbreak: Practical recommendations from a task force of the European CBT-I Academy. J. Sleep Res. 2020, 29, e13052. [CrossRef]

21. Sandín, B.; Valiente, R.; García-Escalera, J.; Chorot, P. Psychological impact of the COVID-19 pandemic: Negative and positive effects in Spanish people during the mandatory national quarantine. J. Psychopathol Clin. Psychol. 2020, 25, 1-21. [CrossRef]

22. Cellini, N.; Canale, N.; Mioni, G.; Costa, S. Changes in sleep pattern, sense of time and digital media use during COVID-19 lockdown in Italy. J. Sleep Res. 2020, 19, e13074. [CrossRef]

23. Pinto, J.; Zeller, M.A.P.va.; Pimentel, A.; Dantas, P.; Eusébio, E.; Neves, A.; Pipa, J.; Santa-Clara, E.; Santiago, T.; Viana, P.; et al. Sleep quality in times of COVID-19 pandemic. Sleep Med. 2020, 74, 81-85. [CrossRef]

24. Baptista, A.P.I.; Perazzo, M.; Pinho, T.; Paiva, S.; Pordeus, I.; Serra-Negra, J. Can children's oral hygiene and sleep routines be compromised during the COVID-19 pandemic? Int. J. Paediatr. Dent. 2021, 31, 12-19. [CrossRef] [PubMed]

25. Paiva, T.; Reis, C.; Feliciano, A.; Canas-Simão, H.M.M.; Gaspar, T.; Tomé, G.; Branquinho, C.; Silva, M.; Ramiro, L.; Bentes, C.; et al. Sleep and awakening quality during COVID-19 confinement: Complexity and relevance for health and behavior. Int. J. Environ. Res. Public Health 2021, 18, 3506. [CrossRef]

26. Soldatos, C.; Dikeos, D.; Paparrigopoulos, T. Athens Insomnia Scale: Validation of an instrument based on ICD-10 criteria. J. Psychosom. Res. 2000, 48, 555-560. [CrossRef]

27. Johns, M. A new method for measuring daytime sleepiness: The Epworth sleepiness scale. Sleep 1991, 14, 540-545. [CrossRef]

28. Behar, E.; DiMarco, I.; Hekler, E.; Mohlman, J.; Staples, A. Current theoretical models of generalized anxiety disorder (GAD): Conceptual review and treatment implications. J. Anxiety Disord. 2009, 23, 1011-1023. [CrossRef]

29. Schwarzer, R.; Jerusalem, M.; Weinman, J.; Wright, S.; Johnston, M. Generalized self-efficacy scale. In Measures in Health Psychology: A User's Portfolio. Causal and Control Belief; NFER-NELSON: Windsor, UK, 1995; pp. 35-37.

30. Horne, J.; Östberg, O. A self-assessment questionnaire to determine morningness-eveningness in human circadian rhythms. Int. J. Chronobiol. 1976, 4, 97-110.

31. Buysse, D.; Reynolds, C.; Monk, T.; Berman, S.; Kupfer, D. The Pittsburgh sleep quality index: A new instrument for psychiatric practice and research. Psychiatry Res. 1989, 28, 193-213. [CrossRef]

32. Crönlein, T.; Langguth, B.; Popp, R. Regensburg Insomnia Scale (RIS): A new short rating scale for the assessment of psychological symptoms and sleep in insomnia. Health Qual. Life Outcomes Vol. 2013, 11, 65. [CrossRef]

33. Dunstan, D.; Scott, N. Norms for Zung's Self-rating Anxiety Scale. BMC Psychiatry Vol. 2020, 20, 90. [CrossRef]

34. Cardeña, E.; Koopman, C.; Classen, C.; Waelde, L.; Spiegel, D. Psychometric properties of the Stanford Acute Stress Reaction Questionnaire (SASRQ): A valid and reliable measure of acute stress. J. Trauma. Stress 2000, 13, 719-734. [CrossRef]

35. Zhang, W.; Xu, H.; Zhao, S. Prevalence and influencing factors of co-morbid depression in patients with type 2 diabetes mellitus: A general hospital based study. Diabetol. Metab. Syndr. 2015, 7, 60. [CrossRef] [PubMed]

36. Xiao, H.; Zhang, Y.; Kong, D.; Li, S.; Yang, N. Social Capital and Sleep Quality in Individuals Who Self-Isolated for 14 Days During the Coronavirus Disease 2019 (COVID-19) Outbreak in January 2020 in China. Med. Sci. Monit. 2020, 26, e923921-1-e923921-8. [CrossRef]

37. Fu, W.; Wang, C.; Zou, L.; Yan, S.; Mao, J. Psychological health, sleep quality, and coping styles to stress facing the COVID-19 in Wuhan, China. Transl. Psychiatry 2020, 10, 225. [CrossRef]

38. Varma, P.; Burge, M.; Meaklim, H.; Junge, M.; Jackson, M. Poor Sleep Quality and Its Relationship with Individual Characteristics, Personal Experiences and Mental Health during the COVID-19 Pandemic. Int. J. Environ. Res. Public Health 2021, 18, 6030. [CrossRef] [PubMed]

39. Casagrande, M.; Favieri, F.; Tambelli, R.; Forte, G. The enemy who sealed the world: Effects quarantine due to the COVID-19 on sleep quality, anxiety, and psychological distress in the Italian population. Sleep Med. 2020, 75, 12-20. [CrossRef]

40. Gualano, M.; LoMoro, G.; Voglino, G.; Bert, F.; Siliquini, R. Effects of COVID-19 lockdown on mental health and sleep disturbances in Italy. Int. J. Environ. Res. Public Health 2020, 17, 4479. [CrossRef]

41. Ramos-Padilla, P.; Villavicencio-Barriga, V.; Cárdenas-Quintana, H.; Abril-Merizalde, L.; Solís-Manzano, A.; Carpio-Arias, T. Eating Habits and Sleep Quality during the COVID-19 Pandemic in Adult Population of Ecuador. Int. J. Environ. Res. Public Health 2021, 18, 3606. [CrossRef]

42. Idrissi, A.J.; Lamkaddem, A.; Benouajjit, A.; Bouaazzaoui, M.; Houari, F.; Alami, M.; Labyad, S.; Chahidi, A.; Benjelloun, M.; Rabhi, S.; et al. Sleep quality and mental health in the context of COVID-19 pandemic and lockdown in Morocco. Sleep Med. 2020, 74, 248-253. [CrossRef] 
43. Gupta, R.; Grover, S.; Basu, A.; Lahan, V.; Avasthi, A. Changes in sleep pattern and sleep quality during COVID-19 lockdown. Indian J. Psychiatry 2020, 62, 370-378.

44. Li, D.-J.; Ko, N.-Y.; Chen, Y.-L.; Yen, C.-F.; Lu, W.-H. COVID-19-related factors associated with sleep disturbance and suicidal thoughts among the taiwanese public: A facebook survey. Int. J. Environ. Res. Public Health 2020, 17, 4479. [CrossRef] [PubMed]

45. Beck, F.; Léger, D.; Fressard, L.; Peretti-Watel, P.; Verger, P. Covid-19 health crisis and lockdown associated with high level of sleep complaints and hypnotic uptake at the population level. J. Sleep Res. 2020, 30, e13119. [CrossRef]

46. Franceschini, C.; Musetti, A.; Zenesini, C.; Riemann, D.; Castelnuovo, G. Poor sleep quality and its consequences on mental health during the COVID-19 lockdown in Italy. Front. Psychol. 2020, 11, 3072. [CrossRef] [PubMed]

47. Trakada, A.; Nikolaidis, P.; Andrade, M.; Knechtle, B.; Trakada, G. Sleep during “lockdown” in the COVID-19 pandemic. Int. J. Environ. Res. Public Health 2020, 17, 9094. [CrossRef]

48. Grey, I.; Arora, T.; Thomas, J.; Tomhe, P.; Abi-Habib, R. The role of perceived social support on depression and sleep during the COVID-19 pandemic. Psychiatry Res. 2020, 293, 113452. [CrossRef]

49. Leone, M.; Sigman, M.; Golombek, D. Effects of lockdown on human sleep and chronotype during the COVID-19 pandemic. Curr. Biol. 2020, 30, R930-R931. [CrossRef]

50. Terán-Pérez, G.; Portillo-Vásquez, A.; Arana-Lechuga, Y.; Sánchez-Escandón, O.; Mercadillo-Caballero, R.; González-Robles, R.; Velázquez-Moctezuma, J. Sleep and Mental Health Disturbances Due to Social Isolation during the COVID-19 Pandemic in Mexico. Int. J. Environ. Res. Public Health 2021, 18, 2804. [CrossRef]

51. Ubara, A.; Sumi, Y.; Ito, K.; Matsuda, A.; Matsuo, M.; Miyamoto, T.; Kadotani, H. Self-isolation due to COVID-19 is linked to small one-year changes in depression, sleepiness, and insomnia: Results from a clinic for sleep disorders in Shiga Prefecture, Japan. Int. J. Environ. Res. Public Health 2020, 17, 8971. [CrossRef] [PubMed]

52. Szovák, E.; Varga, K.; Pelyva, I.; Kívés, Z.; Tóth, Á. Insights gained in the aftermath of the COVID-19 pandemic: A follow-up survey of a recreational training program, focusing on sense of coherence and sleep quality. Int. J. Environ. Res. Public Health 2020, 17, 9201. [CrossRef] [PubMed]

53. Park, J.-H.; Yoo, E.; Kim, Y.; Lee, J.-M. What Happened Pre- and during COVID-19 in South Korea? Comparing Physical Activity, Sleep Time, and Body Weight Status. Int. J. Environ. Res. Public Health 2021, 18, 5863. [CrossRef]

54. Lipert, A.; Kozłowski, R.; Timler, D.; Marczak, M.; Musiał, K.; Rasmus, P.; Kamecka, K.; Jegier, A. Physical Activity as a Predictor of the Level of Stress and Quality of Sleep during COVID-19 Lockdown. Int. J. Environ. Res. Public Health 2021, $18,5811$. [CrossRef]

55. Kontsevaya, A.; Mukaneeva, D.; Myrzamatova, A. hanges in physical activity and sleep habits among adults in Russian Federation during COVID-19: A cross-sectional study. BMC Public Health 2021, 21, 893. [CrossRef] [PubMed]

56. Stanton, R.; To, Q.; Khalesi, S.; Fenning, A.; Vandelanotte, C. Depression, anxiety and stress during COVID-19: Associations with changes in physical activity, sleep, tobacco and alcohol use in Australian adults. Int. J. Environ. Res. Public Health 2020, $17,4065$. [CrossRef]

57. Genta, F.; Neto, G.; Sunfeld, J.; Porto, J.; Xavier, A.; Moreno, C.; Lorenzi-Filho, G.; Genta, P. COVID-19 pandemic impact on sleep habits, chronotype and health-related quality of life among high school students: A longitudinal study. J. Clin. Sleep Med. 2021, 17, 1371-1377. [CrossRef] [PubMed]

58. Marelli, S.; Castelnuovo, A.; Somma, A.; Castronovo, V.; Mombelli, S.; Bottoni, D.; Leitner, C.; Fossati, A.; Ferini-Strambi, L. Impact of COVID-19 lockdown on sleep quality in university students and administration staff. J. Neurol. 2021, 268, 8-15. [CrossRef] [PubMed]

59. Bruni, O.; Malorgio, E.; Doria, M.; Finotti, E.; Spruyt, K.; Melegari, M.; Villa, M.; Ferri, R. Changes in sleep patterns and disturbances in children and adolescents in Italy during the COVID-19 outbreak. Sleep Med. 2021. [CrossRef] [PubMed]

60. Sañudo, B.; Fennell, C.; Sánchez-Oliver, A. Objectively-assessed physical activity, sedentary behavior, smartphone use, and sleep patterns preand during-COVID-19 quarantine in young adults from Spain. Sustainability 2020, 12, 5890. [CrossRef]

61. Romero-Blanco, C.; Rodríguez-Almagro, J.; Onieva-Zafra, M.; Prado-Laguna, M.; Hernández-Martínez, A. Sleep pattern changes in nursing students during the COVID-19 lockdown. Int. J. Environ. Res. Public Health 2020, 17, 5222. [CrossRef]

62. Aguilar-Farias, N.; Toledo-Vargas, M.; Miranda-Marquez, S.; Okely, A.; Cruz, B. Sociodemographic predictors of changes in physical activity, screen time, and sleep among toddlers and preschoolers in chile during the COVID-19 pandemic. Int. J. Environ. Res. Public Health 2020, 18, 176. [CrossRef]

63. Zhang, Y.; Zhang, H.; Ma, X.; Di, Q. Mental Health Problems during the COVID-19 Pandemics and the Mitigation Effects of Exercise: A Longitudinal Study of College Students in China. Int. J. Environ. Res. Public Health 2020, 17, 3722. [CrossRef]

64. Wang, S.; Xie, L.; Yao, X.Y.B.; Xiang, D. Sleep disturbances among medical workers during the outbreak of COVID-2019. Occup. Med. 2020, 70, 364-369. [CrossRef]

65. Xiao, H.; Zhang, Y.; Kong, D.; Li, S.; Yang, N. The effects of social support on sleep quality of medical staff treating patients with coronavirus disease 2019(COVID-19) in January and February 2020 in China. Med. Sci. Monit. 2020, 26, e923549-1-e923549-8. [CrossRef] [PubMed]

66. Kim-Godwin, Y.; Lee, M.; Logan, J.; Liu, X. Factors influencing sleep quality among female staff nurses during the early COVID-19 pandemic in the United States. Int. J. Environ. Res. Public Health 2021, 8, 4827. [CrossRef]

67. Meo, S.; Alkhalifah, J.; Alshammari, N.; Alnufaie, W. Comparison of Generalized Anxiety and Sleep Disturbance among Frontline and Second-Line Healthcare Workers during the COVID-19 Pandemic. Int. J. Environ. Res. Public Health 2021, 18, 5727. [CrossRef] 
68. Johns Hopkins Coronavirus Resource Center. Johns Hopkins Coronavirus Resource Center—COVID; Johns Hopkins Coronavirus Resource Center: Baltimore, MD, USA, 2021. Available online: https:/ / coronavirus.jhu.edu/map.html (accessed on 8 July 2021).

69. WorldOMeters. WorldOMeters: Geneva, Switzerland. 2021. Available online: https:/ / www.worldometers.info/ (accessed on 8 July 2021).

70. Martins, A.; Sobral, S. Working and Learning during the COVID-19 Confinement: An Exploratory Analysis with a Small Sample from Portugal. Informatics 2021, 8, 44. [CrossRef]

71. Sobral, S.; Jesus-Silva, N.; Cardoso, A.; Moreira, F. EU27 Higher Education Institutions and COVID-19, Year 2020. Int. J. Environ. Res. Public Health 2021, 18, 5963. [CrossRef] [PubMed]

72. Sateia, M. International Classification of Sleep Disorders-Third Edition. Contemp. Rev. Sleep Med. 2014, 146, 1387-1394. [CrossRef] [PubMed] 